\title{
Políticas Públicas e Tic na Educação: Dite Sergipe 1994 a 2007
}

\author{
Simone Silveira Amorim \\ Irinea Nunes de Salles Almeida Moura \\ Universidade Tiradentes
}

\begin{abstract}
NUNES, Andrea Karla Ferreira. Políticas públicas e TIC na educação: DITE Sergipe 1994 a 2007. EDUNIT: Aracaju, 2015. 245p. (v. 1).
\end{abstract}

A obra trata de uma análise sobre as potencialidades e fragilidades da Divisão de Tecnologia de Ensino (DITE), instituição responsável pela implantação das Políticas Públicas e efetivação das Tecnologias da Informação e Comunicação (TIC) no Estado de Sergipe entre os anos de 1994 a 2007.

O desejo da autora em pesquisar a trajetória da DITE deveu-se ao fato de conhecer as pesquisas realizadas pelo Núcleo de Pós-Graduação da Universidade Federal de Sergipe (NPGED); pesquisas essas, direcionadas para a coordenação dos programas e projetos federais e locais sobre a implantação e implementação das tecnologias educacionais no estado. Porém, nenhuma das pesquisas estava relacionada à Divisão de Tecnologia de Ensino quanto à criação, à consolidação, à difusão e à implantação de projetos na área de Tecnologias na Educação para as escolas públicas no estado de Sergipe. Para a materialização dessa obra, Nunes (2015) apoiou-se em diversas fontes documentais, tais como: a Legislação; os projetos definidos pelo Ministério da Educação; os relatórios dos coordenadores da Secretaria Estadual de Educação de Sergipe; ofícios; portarias e entrevistas com as partes integrantes na Divisão durante esse período.

A obra está dividida em três partes: As transformações TécnicoCientíficas e Econômicas e as Políticas Educacionais para uso das Tecnologias da Informação e da Comunicação; A Introdução das Tecnologias da Informação e Comunicação em Sergipe e a Criação da Divisão de Tecnologia de Ensino; Concretização e Difusão das Tecnologias da Informação e Comunicação em Sergipe. 
A primeira parte demonstra as mudanças ocorridas na sociedade, advindas das transformações técnico-científicas e o papel do Estado e da economia. Tudo isso contribuiu para a ampliação do conhecimento e da sociedade gerando produtividade e competitividade - e ainda, os órgãos internacionais na orientação das políticas educacionais para o uso das Tecnologias e Comunicação no Brasil.

As Transformações Técnico-Científicas tiveram participação direta nas mudanças sociais e contribuíram também para a expansão do conhecimento e estabelecimento de novas relações com o trabalho e vida das pessoas, exigindo um fluxo maior de desenvolvimento, produtividade e competitividade.

Utilizando-se do estudo da ciência e do conhecimento no campo da História da Educação, Nunes (2015) retrata as modificações no contexto social com base na revolução industrial quando as transformações sociais foram da agrária a industrial, surgindo a necessidade de qualificação por parte dos trabalhadores. A segunda revolução Científica teve início na metade do século XIX e foi caracterizada pelo surgimento do aço, da utilização de energia elétrica, do petróleo, desenvolvimento dos meios de transporte, fatores que resultaram na necessidade de um novo perfil profissional. A segunda 280 metade do século XX, período marcado pelas transformações sociais e tecnológicas e pelas novas formas de organização do trabalho no âmbito da política e do Estado. Para entender esse cenário, a autora relata o esgotamento do Estado intervencionista em virtude da crise internacional, possibilitando a reestruturação dos modelos econômicos.

Segundo Nunes (2015), as Tecnologias da Informação e Comunicação passaram a exercer um papel importante na sociedade capitalista visando ao desenvolvimento do novo perfil do trabalhador para atender às mudanças advindas da globalização. No Brasil, propôs-se a reforma política econômica com base na reorganização do capitalismo.

A segunda parte da obra tem como objetivo descrever o processo de materialização das políticas educacionais no estado de Sergipe, tendo como núcleo de estudo a Divisão Tecnológica de Ensino (DITE), responsável pela divulgação e execução de programas e projetos de Tecnologias da Educação nas escolas públicas sergipanas. Por meio da pesquisa realizada no acervo documental da DITE, a autora traça o quadro político econômico do Estado de Sergipe. 
Segundo a autora, a década de 90 do século XX marca o início do uso das Tecnologias da Educação no Estado de Sergipe, quando houve a implantação do Projeto Educom, Projeto Vídeo Escola, e o Programa Salto para o Futuro.

O projeto Educom esteve vinculado ao Centro de Informática Educativa (CIED/Se), setor responsável pela expansão da cultura, da informática para as escolas públicas e pela capacitação dos professores. O CIED constituiu um espaço de suma importância para o desenvolvimento tecnológico no estado de Sergipe até o ano de 1994. A partir desse momento, surge o Programa Nacional de Informática Tecnológica (Proninfe) instituído pelo Ministério da Educação e Cultura (MEC) e, posteriormente, incorporado à Secretaria do Estado da Educação.

Ainda na segunda parte do livro, a autora apresenta o Projeto Vídeo Escola e o Programa Salto para o Futuro. O Projeto Vídeo Escola teve início no Rio de Janeiro apoiado pelo Banco do Brasil e pela Fundação Roberto Marinho, expandido, posteriormente, para o Norte e Nordeste do País. $\bigcirc$ Programa Salto para Futuro surgiu no ano de 1991, a princípio, em seis estados do País, posteriormente, em 1992, em todo o território nacional.

Apoiada em seus estudos, foi possível para a autora identificar as diversas dificuldades enfrentadas pelo Governo do Estado de Sergipe, mais precisamente pela Secretaria da Educação (SEED/Se). As inúmeras dificuldades a serem superadas estavam no eixo da estrutura física até a compra de pequenos materiais para o funcionamento dos equipamentos. As dificuldades não foram restritas ao campo da estrutura física; era necessário, pois, pensar também na atuação docente.

Com o incremento das atividades e o desejo de receber novos recursos provenientes de outros programas (TV Escola e Proinfem), a Secretaria do Estado da Educação foi impulsionada a buscar um espaço mais apropriado e que abrigasse a equipe que trabalhava no acompanhamento dos projetos e os recursos tecnológicos. A autora relata que membros, depoentes de sua pesquisa, declararam que esse momento foi um marco para implantação da DITE que compunha o Departamento de Educação. Nesse momento, foi institucionalizado um setor para cuidar das políticas educacionais que envolviam a introdução e utilização das Tecnologias da Informação e Comunicação na Educação Sergipana. 
Nunes (2015) fundamentou a criação da DITE por meio do ofício de n. 52/99, de $1^{\circ}$ de janeiro de 1999, o qual faz referência à Divisão, por falta de um documento oficial. Outro documento utilizado pela autora foi - Regimento Interno da Secretaria do Estado da Educação e Desporto e do Lazer (1994) com o qual foi possível comprovar que a DITE fazia parte do Departamento da Educação. No Regimento Interno da DITE, a autora esclarece que, apesar da Divisão estar vinculada ao Ensino Fundamental, sua atuação não se restringiu a essa modalidade de ensino, como descrito no artigo 88, inciso VII. Apoiada no regimento, a DITE direcionou suas atividades para a área pedagógica visando preparar a comunidade escolar a atender ao novo contexto social.

No que se refere à consolidação e dificuldades enfrentadas pela DITE, a autora parte dos seguintes problemas: Quais dificuldades comprometeram o andamento das propostas? Como a divisão se comportou diante dos fatos? Com base nos documentos encontrados, a autora relata que as dificuldades se deram a partir da proposta da Estrutura Administrativa de gestão, da manutenção dos equipamentos, da supervisão e acompanhamentos das ações. No entanto, apesar de todos os percalços, foi possível criar a cultura de uso das 282 Tecnologias na Educação sergipana, consolidando programas e projetos por meio da formação de recursos humanos e as produções acadêmicas em nível Stricto Sensu, decorrentes de ações desenvolvidas pela Divisão.

Na terceira e última parte de sua obra, Nunes (2015) trata da Concretização e Difusão das Tecnologias da Informação e Comunicação de Sergipe. Para análise do processo de consolidação da Divisão, centralizou as investigações no acervo documental, entrevistas, trajetória, resultados das políticas públicas do MEC e nas parcerias mantidas com as fundações e instituições vinculadas aos projetos do Estado.

As Práticas Educacionais estabelecidas a nível Nacional foram realizadas mediante os Projetos: Informática na Educação, Informática da Educação Especial, Programa TV Escola, Formação Continuada em Mídias na Educação.

Quanto à experiência da utilização das TIC na rede pública do Estado, em parceria com outras instituições, Nunes (2015) enfatiza em seu comentário, ao dizer que não dá para querer qualidade na educação e desenvolvimento da sociedade apenas enchendo as escolas de equipamentos tecnológicos ou ainda, cumprindo metas de capacitação docente. No tocante à utilização das 
TIC de iniciativa da SEED e da DITE, a autora narra que a Divisão se consolidou mediante as suas ações, tornando-se evidentes para o Estado devido ao acompanhamento, assessoramento e atuação durante as capacitações docentes.

Trata-se, pois, de uma obra importante para pesquisadores e interessados em conhecer as ações e transformações, ocasionadas na sociedade pelo uso das Tecnologias de Informação e Comunicação.

Prof ${ }^{a}$. Dr ${ }^{a}$. Simone Silveira Amorim Universidade Tiradentes

Programa de Pós-Graduação em Educação Líder do Grupo de Pesquisa Educação e Sociedade: Sujeitos e Práticas

Educativas Grupo de Pesquisa História das Práticas Educacionais | CNPa Grupo de Pesquisa Núcleo de Estudos de Cultura | NECUFS Universidade Federal de Sergipe E-mail | amorim_simone@hotmail.com

Prof ${ }^{a}$. Esp. Irinea Nunes de Salles Almeida Moura

Universidade Tiradentes Gerente dos Cursos Técnicos E-mail | sallesirinea@ig.com.br

Recebido 8 set. 2017 Aceito 6 out. 2017 